\title{
China's Green Lights Program: A review and assessment
}

Fei Guo ${ }^{a}{ }^{1}$, Shonali Pachauri ${ }^{\text {a }}$

a Energy Program, International Institute for Applied Systems Analysis, Schlossplatz 1, A-2361 Laxenburg, Austria

\begin{abstract}
Lighting accounts for $10-13 \%$ of China's electricity consumption. Triggered by the nationwide power shortage of the mid-1990s, the Chinese government launched its Green Lights Program in 1996. Since then, this program has been continuously highlighted in the nation's 9th-12th Five-Year Plans (1996-2015). This paper presents a review and assessment of this program during the past two decades. Based on available data, the achievements along with the implementation of this program are assessed by examining a set of indicators of electricity savings, consumer savings, market penetration, product quality, and production capacity expansion. The success of this programs can be attributed to several factors: 1) strong and sustained government commitment; 2) prioritized policy focus by program stages; 3 ) extensive efforts on product quality control; 4) a close symbiosis of energy efficiency policies with industrial development policies; and 5) the implementation of various incentive schemes. Nonetheless, several challenges are evident that the program needs to address in its next phase. These include: 1) promoting the use of efficient lighting products in rural China; 2) emphasizing the overall efficacy of lighting fixtures rather than focusing only on bulb efficacy; and 3) promoting the healthy development of an emerging semiconductor lighting industry in the nation.
\end{abstract}

Keywords: Green Lights Program, Efficient lighting products, Policy assessment, Product quality control, China

\footnotetext{
${ }^{1}$ Corresponding author. Tel.: +43 2236807 409; fax: +43 2236 71313. E-mail addresses: guof@iiasa.ac.at, guofei2003@gmail.com (F. Guo).
} 


\section{Background}

In the mid-1990s, China was facing a severe power shortage owing to its fast growing economy, population and standard of living. The need to build new power plants competed for insufficient government capital for infrastructure construction, putting significant pressure on the Chinese government (SETC, 1996; Guan et al., 1997; Lin, 1999). This context fostered strong incentives in the Chinese society at that time to seek energy efficiency improvements.

Lighting accounts for a quite stable share of about $10-13 \%$ of China's electricity consumption, and mostly represents peak demand (Lv \& Lv, 2012; CNIS, 2011). Nonetheless, the absolute amount of lighting electricity use increased significantly over the past years along with China's fast economic growth. Figure 1 shows a modeling projection of lighting demand in Chinese buildings, including residential, commercial and industrial buildings, till 2020 from a base year of 2002 (Liu, 2009). According to this projection, the lighting demand ${ }^{2}$ in Chinese buildings in 2020 is projected to be about 2.2 times that in 2002 . This implies an average annual growth rate of about $4.3 \%$.



Figure 1: Lighting demand in Chinese buildings 2002-2020

(Source: based on Liu, 2009)

\footnotetext{
${ }^{2}$ It is worth noting that the lighting demand in this projection is estimated in "lumen-hours" rather than in " $\mathrm{kWh}$ " of electricity consumption mainly because of uncertainties regarding the future development of emerging light-emitting diode (LED) lighting technologies.
} 
Inspired by a similar program initiated by the U.S. Environmental Protection Agency (EPA) in 1993, the Chinese central government launched its own 'Green Lights Program (GLP)' in 1996 as one of the key national energy efficiency activities of its 9th Five-Year Plan (FYP) (1996-2000). The FYP in China comprises the nation's chief social and economic development guideline for its five year implementation period.

China's GLP was initiated and led by the State Economic and Trade Commission (SETC) in coordination with some other Chinese central government agencies ${ }^{3}$ (Liu, 2006). The program office was subsequently established, including a leader group, expert group and project office. Since then, this program has continued on through China's 10th, 11th, and 12th FYP as part of a key national campaign of energy efficiency improvement. The SETC was terminated in 2003 because of intuitional reforms of the government, and the lead responsibility for this program was subsequently assigned to the National Development and Reform Commission (NDRC).

As stated in the program launch document by the SETC (1996), the principal objectives of this program were to save electricity use in the nation and associated pollutant emissions, to slow down the rapidly rising investment needs for constructing new power generation facilities, and to provide high-quality efficient lighting products to consumers. Along with the program's progress, expanding the manufacturing capacity of China's lighting industry for efficient products became an additional and important objective as well, although this was not explicitly indicated when the program was launched.

In practice, the core of this program aimed at replacing low-efficiency lighting lamps by socalled 'high-efficiency lighting products', including T8/T5 fluorescent tubes, compact fluorescent lamps (CFLs), and high pressure sodium (HPS) and metal halide (MH) lamps. The T8/T5 fluorescent tubes were used to replace T12/T10 tubes in large lighting areas of commercial and industrial buildings; CFLs were mainly for residential applications owing to their screw-in base design that is convenient for replacing incandescent lamps (ILs) in households; the HPS and MH lamps were primarily for outdoor lighting, such as road lights,

\footnotetext{
${ }^{3}$ The involved central government agencies at that time included the State Planning Commission, Ministry of Science and Technology, Ministry of Information Industry, State Environmental Protection Administration, Ministry of Agriculture, and State Bureau of Quality and Technical Supervision.
} 
and used to replace inefficient high pressure mercury-vapor lamps. A summary of the typical performance of these lamps is presented in Table 1.

Table 1: Typical performance of various types of lamps

\begin{tabular}{|c|c|c|c|c|}
\hline Lamp type & $\begin{array}{c}\text { Luminous } \\
\text { efficacy } \\
\text { (Im/W) }\end{array}$ & $\begin{array}{c}\text { Color-rendering } \\
\text { index (CRI) }\end{array}$ & $\begin{array}{c}\text { Correlated color } \\
\text { temperature (CCT) } \\
\text { (K) }\end{array}$ & $\begin{array}{c}\text { Lifetime } \\
\text { (hours) }\end{array}$ \\
\hline Incandescent lamps (ILs) & 15 & $95-100$ & $2,700-2,800$ & 1,000 \\
\hline $\begin{array}{c}\text { Compact fluorescent } \\
\text { lamps (CFLs) }\end{array}$ & $50-60$ & $77-88$ & $2,700-6,500$ & 8,000 \\
\hline $\begin{array}{c}\text { High pressure mercury- } \\
\text { vapor lamps }\end{array}$ & 50 & 45 & $3,300-4,300$ & 6,000 \\
\hline $\begin{array}{c}\text { Metal halide (MH) } \\
\text { lamps }\end{array}$ & $70-115$ & $65-92$ & $3,000-4,200$ & $6,000-30,000$ \\
\hline $\begin{array}{c}\text { High pressure sodium } \\
\text { (HPS) lamps }\end{array}$ & $100-140$ & $23 / 60 / 85$ & $1,950 / 2,200 / 2,500$ & $16,000-40,000$ \\
\hline $\begin{array}{c}\text { T12/T10 fluorescent } \\
\text { lamps }\end{array}$ & $70-80$ & $65-80$ & $2,700-6,500$ & $15,000-18,000$ \\
\hline T8 fluorescent lamps & $80-90$ & $75-90$ & $2,700-6,500$ & $20,000-24,000$ \\
\hline T5 fluorescent lamps & $95-105$ & $75-90$ & $2,700-6,500$ & $18,000-20,000$ \\
\hline LED lamps (present) & $60-150$ & $70-90$ & $2,700-6,500$ & $25,000-50,000$ \\
\hline
\end{tabular}

(Sources: based on U.S. DOE, 2017; U.S. DOE, 2013; Aman et al., 2013; PNNL, 2009; Liu, 2009; LRC$\mathrm{RPI}, 2002)$

Besides the use of the term 'high-efficiency lighting products', the term 'energy-saving lamps' ${ }^{4}$ is also often used in the context of China's Green Lights Program. Technologically speaking, 'energy-saving lamps' represents only CFLs (Lv \& Lv, 2012). It is also worth noting that the emerging LED lamps are not covered by either of the above two terms under this program, however both LED lamps and 'high-efficiency lighting products' are often called 'efficient lighting products' in Chinese literature.

In what follows, Section 2 presents a brief overview of this program with a focus on the changes in program strategy by stages. A program assessment based on a set of indicators regarding the main achievements and outstanding challenges of this program is included in Section 3. Section 4 then summarizes the significant lessons learnt from this program, which

\footnotetext{
${ }^{4}$ In Chinese, 'high-efficiency lighting products' is referred to as 'Gao Xiao Zhao Ming Chan Pin', while 'energysaving lamps' is referred to as 'Jie Neng Deng'.
} 
can be referenced by other developing countries in designing similar programs. Section 5 provides concluding remarks.

\section{Strategy changes of China's Green Lights Program by stages}

Since its launch in 1996, China's 'Green Lights Program' has been implemented for two decades so far. Examining the changes in the program strategy, the progress of this program can be grouped sequentially in four stages: 1) Stage I (1996-1998) focused on raising the awareness of the general public on 'high-efficiency lighting products'; 2) Stage II (19992006) aimed to promote and regulate the quality of domestic lighting products; 3) Stage III (2007-2010) targeted expediting the diffusion of CFLs by means of financial and mandatory incentives; and 4) Stage IV (after 2010) started to shift the previous program priority from CFLs to emerging LED lighting technologies. A brief description of these four sequential stages of the program is presented below.

\subsection{Stage I - Raising public awareness about efficient lighting products (1996-1998)}

Before the launch of this program, a household survey covering four regions from north to south China, namely Beijing, Suzhou, Dalian and Guangdong, was implemented to determine people's awareness and attitudes towards CFLs. The survey found that only about one-tenth of Chinese households at that time had ever used CFLs, and the popular public attitude to using CFLs was 'Saves Electricity but Not My Money' (Yu \& Zhou, 2001).

The general public had little awareness of efficient lighting, and this was actually closely related to the reality of China's lighting industry and market in the mid-1990s. At that time, the production of 'high-efficiency lighting products' in China was in its very initial stage. Most Chinese producers were small-sized enterprises with poor manufacturing technology, such as manual assembly lines, and the industry was unable to provide consumers with high-quality products. Table 2 and 3 shows that the 'high-efficiency lighting products' manufactured in China at that time lagged far behind similar international products, such as those manufactured by Philips and Osram, in performance. 
Table 2: Lamp lifetime for products from Chinese and Western producers in early 1990s

\begin{tabular}{|c|c|c|c|}
\hline \multirow{2}{*}{ Producers } & \multicolumn{3}{|c|}{ Lamp lifetime (hours) } \\
\cline { 2 - 4 } & Linear Fluorescent & Compact Fluorescent & High Pressure Sodium \\
\hline China & $3,000-5,000$ & $1,000-3,000$ & $4,000-12,000$ \\
\hline Western & $10,000-20,000$ & $5,000-20,000$ & $10,000-25,000$ \\
\hline
\end{tabular}

(Source: Guan et al., 1997)

Table 3: Lamp luminous efficacy for products from Chinese and Western producers in early 1990s

\begin{tabular}{|c|c|c|c|}
\hline \multirow{2}{*}{ Lamp type } & \multicolumn{3}{|c|}{ Luminous efficacy (Im/W) } \\
\cline { 2 - 4 } & China & Typical Western & Best Western \\
\hline Linear Fluorescent (T8) & 50 & 90 & 95 \\
\hline Compact Fluorescent & 50 & 60 & 80 \\
\hline High-intensity Discharge & 40 & 100 & 120 \\
\hline
\end{tabular}

(Source: Guan et al., 1997)

In short, the Chinese lighting market in the mid-1990s was flooded by poor-quality lighting products mainly because of low manufacturing technology and the use of poor raw materials. Consequently, consumers at that time lost their confidence in efficient lighting, and had almost no incentive to buy CFLs.

To address this awareness barrier, the prioritized focus of China's GLP at this stage was, therefore, placed on raising public awareness of the benefits of applying efficient lamps. Various relevant publicity activities were designed and implemented to this end (Liu, 2012). A demonstration center was established in Beijing in 1996, where seventy-four Chinese lighting manufacturers from eighteen provinces presented their efficient lighting products. Five sales centers in four cities in China, namely Beijing, Shanghai, Nanjing and Zhengzhou, were also established. In these sales centers, consumers could buy efficient lighting products from twelve ISO9000-passed Chinese producers with a one-year quality guarantee. Plenty of pamphlets and popular materials were also disseminated to the general public by governments at different levels.

\subsection{Stage II - Promoting the quality of domestic lighting products (1999-2006)}

People's willingness to buy efficient lamps must be supplemented by the availability of good quality products. To address the supply barrier of quality lighting products in the Chinese 
market, the focus of China's GLP lay primarily in promoting product quality control systems in the country since 1999.

These efforts included: 1 ) issuing national performance standards for 'high-efficiency lighting products'; 2) establishing an 'energy conservation certification' scheme for lighting products; 3) improving the technological ability of different 'national lighting test centers' to reach the same high standards; and 4) conducting an annual nation-wide sampling test of CFLs at both factories and in the marketplace.

The issued national standards helped remove unqualified small producers from the market. In 1999, the energy efficiency standard for 'tubular fluorescent lamps (FLs) (GB 17896-1999)' was issued by the government. 'GB 17896-1999' was China's first energy efficiency standard for lighting products, and represented the nation's earliest efforts on establishing a unified technological foundation for the quality of domestic lighting products. From 2004 to 2006, more mandatory national energy efficiency standards for various lighting products were issued, such as 'double-capped FLs (GB19043-2003)', 'self-ballasted FLs (GB19044-2003)', 'single-capped FLs (GB19415-2003)', 'high-pressure sodium vapor lamps (GB19573-2004)', 'ballast for high-pressure sodium lamps (GB19574-2004)', 'metal halide lamps (GB1200542006)', and 'ballast for metal halide lamps (GB120053-2006)'. In addition, one lighting design standard in buildings (GB50034-2004) was also issued, which provided detailed lighting requirements in various buildings, such as for the selection of lighting lamps or fixtures, required illuminance, limits of lighting power density (LPD), etc. These national standards had a fundamental impact on both the production and the use of efficient lighting products in the country. To help domestic manufacturers meet these standards, the Chinese governments at different levels provided certain financial support, such as soft loans, to upgrade the production technology, mainly by supporting R\&D, and importing advanced automatic manufacturing equipment from developed countries (Liu, 2012).

A voluntary 'energy conservation certification' scheme for 'high-efficiency lighting products' was established under the supervision of the China Quality Certification Center (CQC) in 2002. Under this scheme, a total of about 600 models of eight product types from forty-six Chinese manufacturers were certified as of 2005 (Liu, 2012). Figure 2 shows the 'energy conservation certification' stamp for lighting products. This certification scheme largely 
facilitated the late adoption of many other incentive polices in this program, such as government procurement, utility-based demand side management (DSM), and energy performance contracts (EPC) by energy service companies (ESCOs).

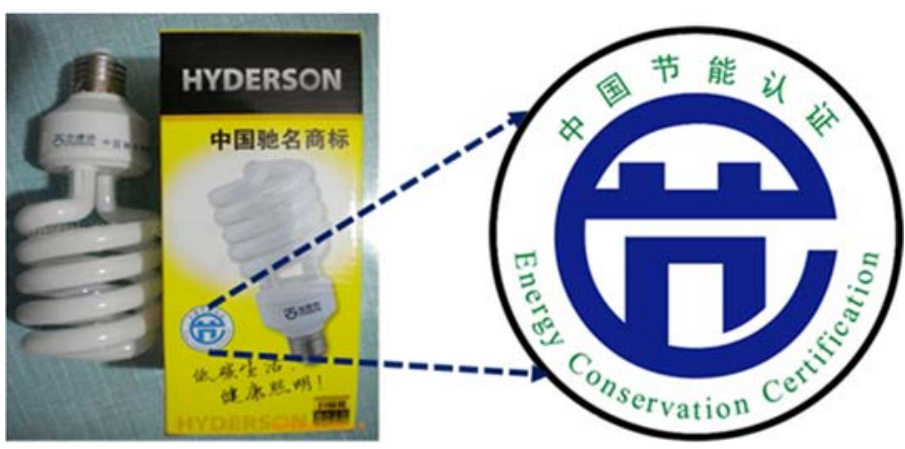

Figure 2: Energy-conservation certification stamp on lighting products in China (Picture from: http://pfybdlali.b2b.huishangbao.com/)

During this period, one thing that often brought disorder to the lighting market from the government side was often-observed inconsistencies in quality testing results among different national lighting test centers (NLTC). To tackle this issue, the central government invested in upgrading the technological conditions of testing centers located in different cities to the same standard as leading international test laboratories that are accredited by the U.S. National Voluntary Laboratory Accreditation Program (Liu, 2012).

These policies significantly facilitated the promotion of quality domestic lighting products in China. Since 1998, the Chinese government conducted an annual national sampling test of CFLs in the marketplace. The compliance rate as a share of total CFL output (pieces) meeting the national standards increased significantly from about $50 \%$ in 1998 , to $80 \%$ in 2005 , and nearly 90\% in 2007 (see Figure 3). The annual sampling test was conducted by China's General Administration of Quality Supervision, Inspection and Quarantine (AQSIQ), and occurred randomly in about 13-15 provinces of China, namely around half of the total provinces in the country. It usually covered about $50-60 \%$ of the CFLs available in the market (by production batches), and tested the products from about 40-70 dominant Chinese manufacturers (USAID, 2010; NDRC, 2005). The test involves five safety indicators and eight performance indicators, which are stipulated in relevant national standards, namely 
GB16844 (safety requirements) and GB/T17263 (performance requirements). It must be noted that all the five safety indicators and two of the eight performance indicators, namely 'energy efficiency' and 'lumen maintenance', are mandatory for the sampling test, while the other six performance indicators are only voluntary for the test (USAID, 2010). The compliance rate issued by the AQSIQ is built based on all involved mandatory indicators. This implies that the compliance rate shown in Figure 3 reveals how many inspected products meet at least the minimum energy efficiency requirements.

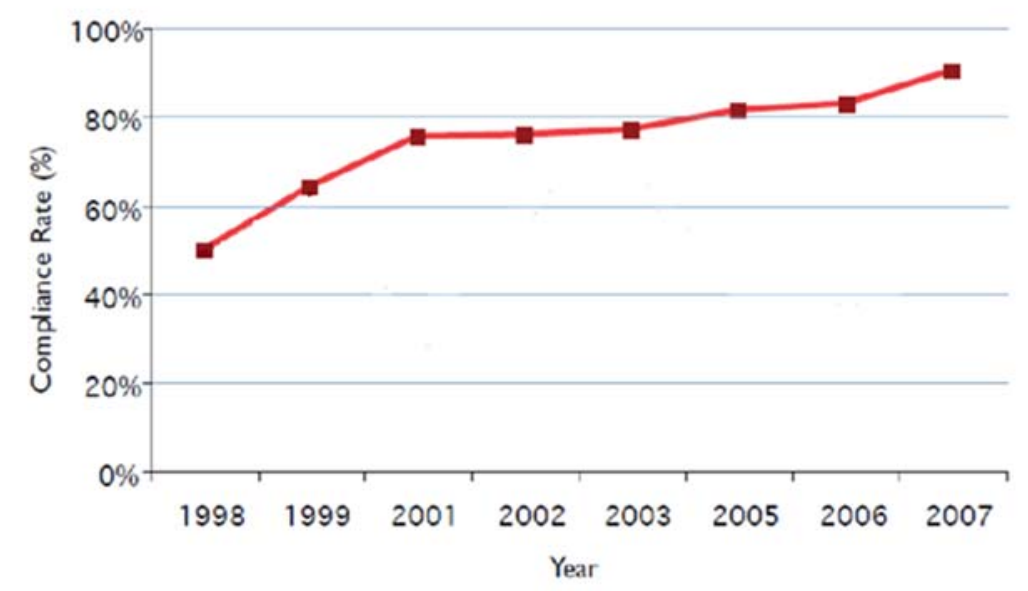

Figure 3: Compliance rate of output for CFLs in China

(Source: USAID, 2010)

Luminous efficacy (Im/w) and lifetime (hours) are the two crucial quality features of CFLs. With the extensive policy efforts on promoting the quality of domestic lighting products at this stage, both the luminous efficacy and lifetime of China's domestic CFLs were significantly improved. Table 4 presents a comparison of luminous efficacy standards of CFLs in China, Japan and the U.S. It can be seen that China's minimum energy performance standard (MEPS) is stricter than that of the U.S. MEPS at lower wattages $(<15 \mathrm{~W})$, but looser at higher wattages. China's Tier-2 standard is a bit stricter than the U.S. Energy Star, while its Tier-1 is roughly at the same level as Japan's Top-runner standard. As in 2010, Tier-1 and Tier-2 CFLs already accounted for about $72 \%$ of the market share (CNIS, 2011), one can further conclude that the overall energy efficiency level of CFLs in China comply with the U.S. Energy Star standard. The CFL lifetime requirement in China's national standard is no 
less than 6,000 hours, which is at the same level as that in many developed countries (see Table 5).

Table 4: Comparison of CFL luminous efficacy standards in China, Japan and the U.S.

\begin{tabular}{|l|c|c|c|c|c|c|}
\hline \multirow{2}{*}{ Power } & \multicolumn{6}{|c|}{ National standards (efficacy unit: Im/W) } \\
\cline { 2 - 7 } & $\begin{array}{c}\text { China } \\
\text { MEPS (Tier-3) }\end{array}$ & $\begin{array}{c}\text { China } \\
\text { EE (Tier-2) }\end{array}$ & $\begin{array}{c}\text { China } \\
\text { Top (Tier-1) }\end{array}$ & $\begin{array}{c}\text { Japan } \\
\text { Top-Runner }\end{array}$ & $\begin{array}{c}\text { U.S. } \\
\text { MEPS }\end{array}$ & $\begin{array}{c}\text { U.S. } \\
\text { Energy Star }\end{array}$ \\
\hline 10W & 48 & 58 & 66 & 60.6 & 45 & 55 \\
\hline 11W & 48 & 58 & 66 & 67.5 & 45 & 55 \\
\hline 12W & 48 & 58 & 66 & 67.5 & 45 & 55 \\
\hline 13W & 48 & 58 & 66 & 67.5 & 45 & 55 \\
\hline 14W & 48 & 58 & 66 & 67.5 & 45 & 55 \\
\hline $15 \mathrm{~W}$ & 55 & 65 & 73 & 67.5 & 60 & 65 \\
\hline $16 \mathrm{~W}$ & 55 & 65 & 73 & 72.4 & 60 & 65 \\
\hline 17W & 55 & 65 & 73 & 72.4 & 60 & 65 \\
\hline 18W & 55 & 65 & 73 & 72.4 & 60 & 65 \\
\hline 19W & 55 & 65 & 73 & 72.4 & 60 & 65 \\
\hline $20 \mathrm{~W}$ & 55 & 65 & 73 & 72.4 & 60 & 65 \\
\hline $21 \mathrm{~W}$ & 55 & 65 & 73 & 72.4 & 60 & 65 \\
\hline $22 \mathrm{~W}$ & 55 & 65 & 73 & 72.4 & 60 & 65 \\
\hline $23 \mathrm{~W}$ & 55 & 65 & 73 & 72.4 & 60 & 65 \\
\hline
\end{tabular}

(Source: CLASP, 2011)

Table 5: Comparison of CFL lifetime requirements in several standards

\begin{tabular}{|l|l|}
\hline \multicolumn{1}{|c|}{ Standards } & \multicolumn{1}{c|}{ Lifetime requirements for CFLs } \\
\hline China, GB/T 17263.2002 & No less than 6,000h \\
\hline Australia/New Zealand, AS/NZS 4847 & $\begin{array}{l}\text { Life of the median lamp (or 11th of sample size of 20) } \\
\text { shall be greater than 6,000h }\end{array}$ \\
\hline EU, EC No 244/2009 & $\begin{array}{l}\text { Lamp survival factor at 6,000h }>=0.5 \text { (life of the median } \\
\text { lamp shall be greater than 6,000h); }\end{array}$ \\
\hline IEC 60969-2001 Edition 1.2 & No less than manufacturer's declaration \\
\hline U.K. EST Lamp Spec, V7.0-2010 & $\begin{array}{l}\text { 1. Bare CFLs must be }>=10,000 \mathrm{~h} \text { for T3 or higher tubes; } \\
\text { or >=8,000 for T2 or lower tubes; } \\
\text { 2. Covered and Reflector CFLs must be }>=6,000 \mathrm{~h} .\end{array}$ \\
\hline U.S. ENERGY STAR V4.2 & $\begin{array}{l}\text { Comply with manufacturer's declaration, but no less } \\
\text { than 6,000h }\end{array}$ \\
\hline
\end{tabular}

(Source: CLASP, 2011) 


\subsection{Stage III - Expediting the diffusion of energy-saving lamps by various incentive schemes}

(2007-2010)

With the previous decade's extensive efforts on raising the public's awareness and buildingup an essential technological foundation for the industry, the focus of China's GLP after 2006 was mainly placed on expediting the diffusion of efficient lighting products on the demand side.

In 2008, the NDRC and Ministry of Finance (MOF) jointly launched a national subsidy program for the purchase of efficient lighting products by bulk purchasers and households. The implementation of this subsidy program was done in two steps: 1) the NDRC called for bids to seek qualified manufacturers with the most reasonable product prices; and 2) the successful bid manufacturers received a subsidy directly from the central government. They were subsequently required to deduct the subsidy from their bidding price to set the final product price for end-users. In this way, both the quality and cost of efficient lighting products could be effectively controlled. The subsidy level was $30 \%$ of the biding price for bulk purchasers and 50\% for households (Liu, 2012). From 2008-2010, a total of 2 billion Chinese Yuan (about 240 million USD) from the central government budget was spent for the subsidy program (Lv \& Lv, 2012). Provincial and city governments also launched their own local subsidy programs in addition to the national program. The local subsidy levels usually varied from $10 \%$ to $40 \%$ of product price depending on the budgets. As an example, the government of Beijing Municipality in 2008 provided local households with a $40 \%$ extra subsidy on top of the national subsidy level. This implied that the CFL cost for Beijing households was only about one-tenth of the original price.

Besides subsidy programs, the NDRC of China and the United Nations Development Programme (UNDP) jointly launched a program called "Light and Love Tour" in 2009. Under this program, between 2009 and 2010 a total of one million CFLs donated by various domestic and international manufacturers, including Philips, Yankon and Panasonic, were distributed to certain relatively less-developed regions across China, and installed for free in households and at schools (Liu et al., 2011).

At this stage, the diffusion of efficient lighting products was widely promoted. In 2010, the total indoor lighting bulbs used in China was about 7.14 billion pieces, while the stock of 
'high-efficiency lighting products' was 5.17 billion pieces (see Table 6). This indicated an overall market penetration of $72.4 \%$ for efficient lighting products in China, a big jump from the estimate of about $47 \%$ in 2006 (Liu, 2006). Specifically, the penetration rate was about $61.5 \%, 90.1 \%$ and $82.6 \%$ respectively for residential, commercial and industrial buildings (See Table 6). It is worth noting that compared to commercial and industrial buildings, the penetration rate of efficient lamps in residential buildings, mainly CFLs, is relatively much lower.

Table 6: Market penetration of indoor lighting bulbs in China in 2010

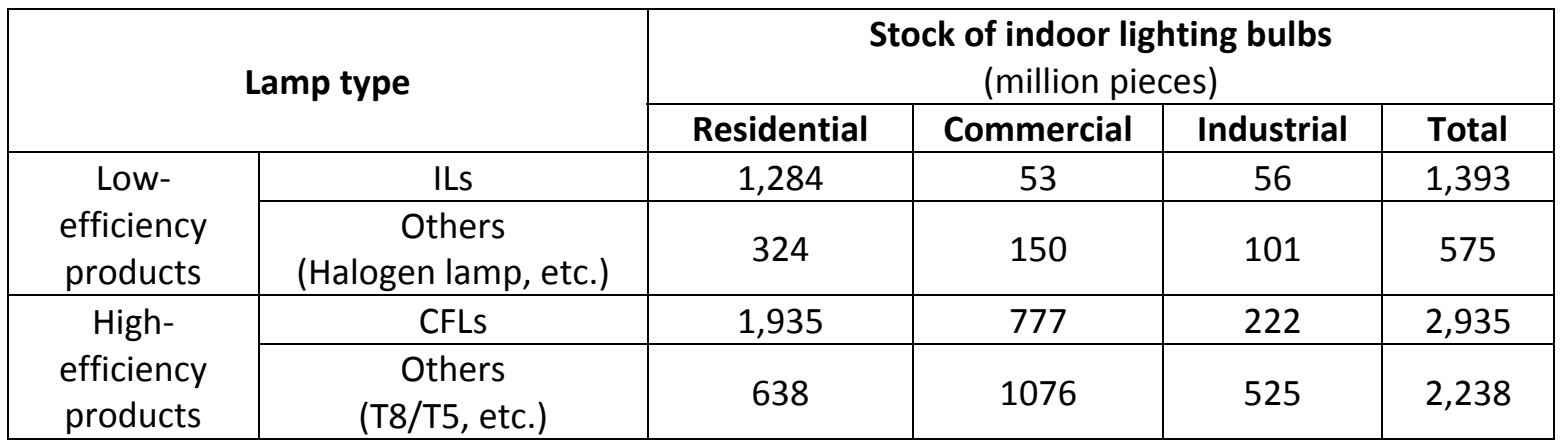

(Source: Lv \& Lv, 2012)

To better facilitate the widespread use of CFLs in China, in 2009 the Chinese central government started to design the phasing-out roadmap of incandescent lamps (ILs) in the nation through a joint project with the UNDP and the Global Environment Facility (GEF), called 'Phasing-out of Incandescent Lamps \& Energy Saving Lamps Promotion (PILESLAMP)' (UNDP, 2009). On the basis of this project, the NDRC in 2011 finally issued the 'Notice of Prohibiting the Sale and Import of Incandescent Bulbs'. This notice stated that China would mandatorily phase out the sale and import of ordinary incandescent bulbs by stages. Specifically, the notification stated that incandescent bulbs of 100 watts and above would not be allowed for sale in the Chinese market after October 1, 2012; 60 watt and above after October 1, 2014; 15 watt and above after October 1, 2016.

\subsection{Stage IV - Shifting program focus to emerging LED lighting technologies (after 2010)}

The LED lighting technology has gradually matured over the past decade, and some LED products have started to become available in the Chinese market since 2010. Attracted by the promising prospect of an LED lighting industry, such as potential high lighting efficacy 
and longer lifetime, the NDRC in line with five other central government agencies issued the 'Notice of Developing the Semiconductor Lighting Industry (NDRC-2009-2441)' in 2009. In this document, the guidelines, objectives and key tasks for fostering and promoting LED lighting technology and industry in China were described for the first time.

In 2012, the NDRC jointly with the Ministry of Finance (MOF) and Ministry of Science and Technology (MOST) issued a notice on subsidizing LED lighting products (NRDC-2012-2671). This notice stated that for bulk purchasers of LED lighting products for commercial buildings and roads, the government would provide a subsidy of $30 \%$ of the contract prices of products from thirty-nine qualified LED lamp producers. Encouraged by this national LED incentive policy, local governments also issued various incentives for developing a LED lighting industry in their jurisdictions. For example, in Guangdong province, which is one of the biggest lighting products manufacturing bases in China, the city of Jiangmen provided a subsidy of $6-8 \%$ to LED lighting manufacturing investments in the city for three years (Jiangmen city government, 2013); the city of Zhongshan returned all the electricity-saving benefits from LED lighting projects back to investors (Sina News, 2014).

Facilitated by these government incentives, the LED industry experienced fast growth in China during the $12^{\text {th }}$ FYP (2011-2015). The efficacy of domestic white LED lamps increased from about $100 \mathrm{~lm} / \mathrm{W}$ in 2011 to about $150 \mathrm{~lm} / \mathrm{W}$ in 2015. In this period, the average growth rate of the LED industry in China in terms of sales (in Yuan) was about 30\% annually. In 2015, LED lamps accounted for about $28 \%$ of the total lighting market in China in terms of sales (in Yuan). The total number of LED lamps produced in China was about 6 billion pieces in 2015, and half of these were exported worldwide (Pan et al, 2016).

Recently, LED lamps have become more affordable, and present several environmental and health advantages over CFLs. These lamps produce no mercury pollution and are considered better for people's eyesight. LED lighting instead of CFLs has now gradually become the primary focus of China's Green Lights Program, and this trend is expected to continue over the next phase of this program.

\subsection{Summary of the program progress}

At the time of the launch of this program, namely mid-1990s, there were mainly three significant barriers to disseminating 'high-efficiency lighting products' in China: low 
awareness by the general public, poor product quality, and high initial cost. These barriers were successfully addressed in turn by specific policies over sequential stages of this program. To overcome the awareness barrier, various publicity, education and training programs were conducted nationwide. For overcoming the quality barrier, the government established a solid technological foundation for the lighting industry and market, mainly by including mandatory national standards, a product certification scheme, an energy efficiency labeling scheme, and a sample testing system. For overcoming the cost barriers, extensive subsidy programs were launched by governments at various levels, and additionally, support by the government for production capacity expansion in certain regions to form significant industrial clusters also helped lower product costs through economies of scale.

Various policy incentives were adopted for China's Green Lights Program. The policies applied can be grouped into several sets: production capacity expansion, product quality control, information tools, education and training campaigns, and demand stimulation (summarized in Figure 4).

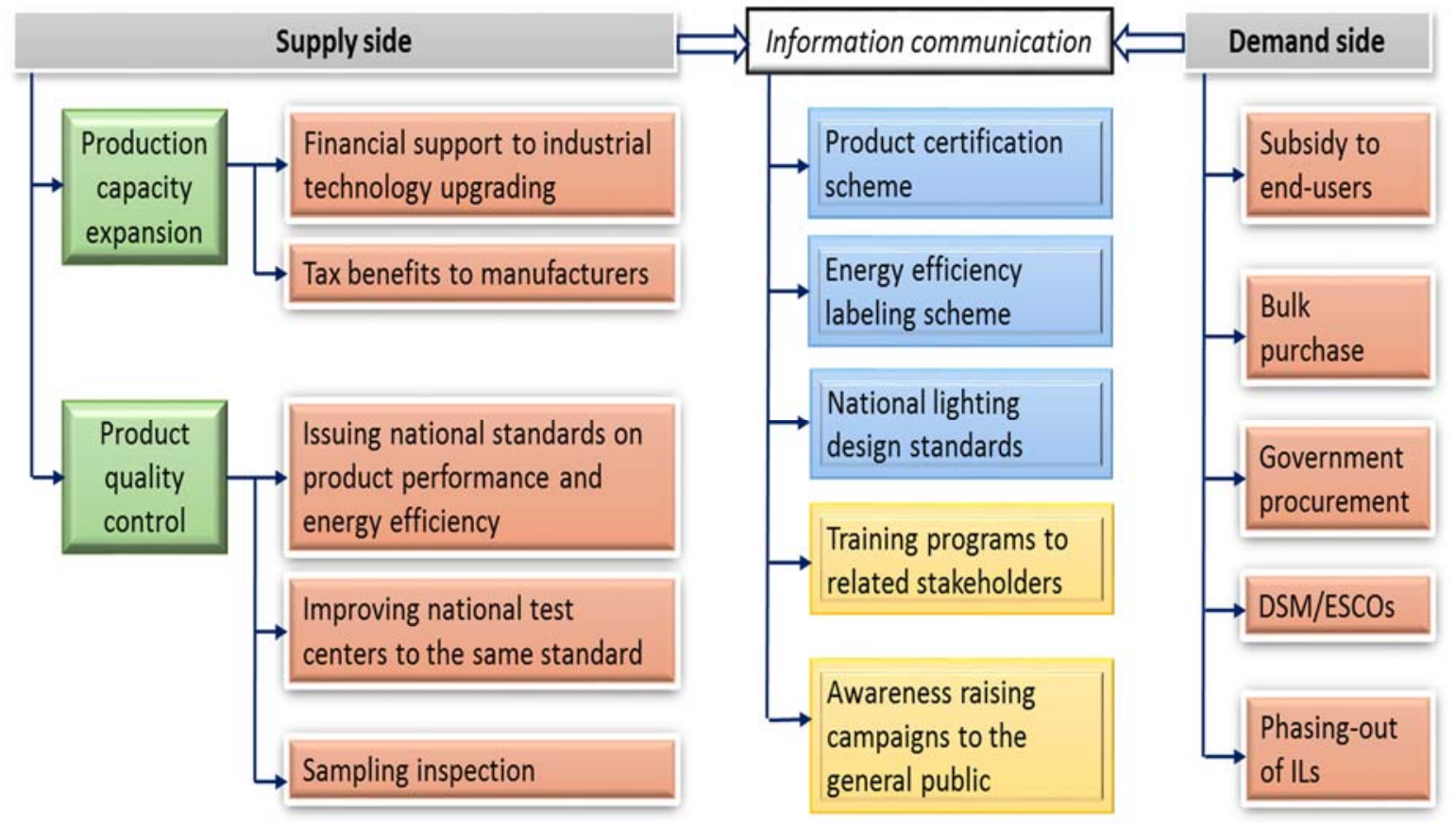

Figure 4: Main polices involved in China's Green Lights Program

(Source: authors' own summary) 
It is evident that this program targeted both the supply and demand sides of the lighting market. On the supply side, the program's efforts were on expanding production capacity and improving product quality of domestic manufacturers. On the demand side, attention was focused on removing cost and information barriers to consumers about efficient lighting products. The underlying overarching strategy of China's Green Lights Program on production capacity expansion was to attract private investment in the manufacture of qualified efficient lighting products primarily by encouraging and facilitating the use of such products on the demand side. The demand-enhancing measures mainly included subsidy programs to end-users, utility-based demand side management (DSM), government procurement, and a ban on the sale and import of incandescent bulbs.

\section{Program Assessment}

\subsection{Methods and Data}

This program brought not only environmental benefits but also economic benefits to the nation. Therefore, based on available data a set of indicators reflecting the main achievements of this program are analyzed, including electricity savings, consumer savings, production capacity expansion, and export income. In addition, the challenges that remain for this program and need to be addressed in the next phase are also summarized.

There was no built-in mechanism for monitoring this program, and therefore no official program assessment reports were regularly issued. During the past two decades, only one report regarding the performance of this program was published by the Chinese government (NDRC, 2005). Besides this, the Energy Research Institute (ERI) under China's NDRC, published several articles and books summarizing the status of program implementation from time to time, which provide additional information essential for an assessment of the program (Yu \& Zhou, 2001; Liu, 2006; Liu, 2009; Liu et al., 2011; Liu, 2012; Lv \& Lv, 2012). The data from China's Illuminating Engineering Society (CIES, 2014; CIES, 2016) were also referenced for this assessment. In addition, several international and U.S. organizations also conducted analyses of China's Green Lights Program, including the Lawrence Berkeley National Laboratory (LBNL) and the American Council for an EnergyEfficient Economy (ACEEE) (Nadel et al., 1999; Lin, 1999), the U.S. Agency for International 
Development (USAID, 2010), the United Nations Development Programme (UNDP, 2009), and the Collaborative Labeling and Appliance Standards Program (CLASP, 2011). These are other important sources of data for assessing this program. In short, this paper is built on these existing data sources from both within and outside China.

\subsection{Main achievements}

\subsubsection{Electricity savings}

According to the data released by the ERI under China's NDRC (SCIO, 2006), China's 'Green Lights Program' resulted in about 59 billion kWh of accumulated electricity savings from 1996 to 2005. This electricity saving led to a reduction of 17 million tons of $\mathrm{CO}_{2}$ emissions and 530 thousand tons of $\mathrm{SO}_{2}$ emissions during this period. During the 11th FYP period (2006-2010), it is estimated that this program resulted in 14.4 billion kWh of electricity savings annually (Lv \& Lv, 2012). This saving is equivalent to about $3 \%$ of the yearly electricity consumption in Chinese households during the period.

\subsubsection{Consumer savings}

Following the implementation of this program, the price of CFLs in China significantly dropped because of economies of scale and substantial expansion of production capacity. In 1994, CFLs in China cost about 40 Yuan/piece for domestic products and 100 Yuan/piece for internationally branded products (Nadel et al., 1999). In current prices, these would be about 86 Yuan/piece and 215 Yuan/piece respectively (applying GDP deflator values from World Bank, 2017). At present the cost of these is only about 5-10 Yuan/piece for domestic brands and 10-20 Yuan/piece for international brands (like Philips and Osram) (Suning, 2017). This implies that the current CFL price in China is generally less than one-tenth of what it was two decades ago in terms of real prices.

Compared to ILs, the lamp efficacy (lumens/watt) of CFLs is much higher and the lifetime (hours) is much longer. Table 7 shows a typical replacement scheme of ILs by CFLs in households, which provides the same lumen needs for lighting. It shows that for a typical lifetime of CFLs $(8,000$ hours), one could save a total cost of about 178 Yuan with this replacement scheme, implying a $70 \%$ cost savings for consumers. The payback time for 
purchasing CFLs in this scheme is only about 3 months, given the average lighting time of 4 hours/bulb·day in Chinese households (Zheng et al., 2015).

Table 7: Consumer savings from a typical replacement scheme of ILs by CFLs in China

\begin{tabular}{|c|c|c|c|c|c|c|}
\hline \multirow{2}{*}{$\begin{array}{c}\text { Lamp } \\
\text { type }\end{array}$} & \multicolumn{3}{|c|}{ Attributes of lamps } & \multicolumn{3}{c|}{ The total cost for lighting 8,000 hours } \\
\cline { 2 - 6 } & Wattage & $\begin{array}{c}\text { Price } \\
\text { (W) }\end{array}$ & $\begin{array}{c}\text { Typical } \\
\text { (Yuan/piece) } \\
\text { (hotime } \\
\text { (hours) }\end{array}$ & $\begin{array}{c}\text { Purchase cost } \\
\text { (Yuan) }\end{array}$ & $\begin{array}{c}\text { Electricity cost } \\
\text { (Yuan) }\end{array}$ & $\begin{array}{c}\text { Total cost } \\
\text { (Yuan) }\end{array}$ \\
\hline ILs & 60 & 1.0 & 1,000 & 8.0 & 240.0 & 248.0 \\
\hline CFLs & 15 & 10.0 & 8,000 & 10.0 & 60.0 & 70.0 \\
\hline
\end{tabular}

Note: [1] the purchase prices for ILs and CFLs are found from suning.com (as of May 2017), and the CFL price is the average of international and domestic brands; [2] using the average household electricity price in China, 0.5 Yuan/kWh (Zhang \& Qin, 2015);

(Source: authors' own calculation based on Suning, 2017; Zhang \& Qin, 2015)

\subsubsection{Production capacity expansion}

The CFL production capacity in China experienced fast growth since the launch of the program in 1996 (see Figure 5). Many domestic companies started to enter this business, and a number of international leading companies established their manufacturing facilities in China. It is worth noting that CFL production has shown a slightly decreasing trend since 2013, mainly because of competition from emerging LED lamps.

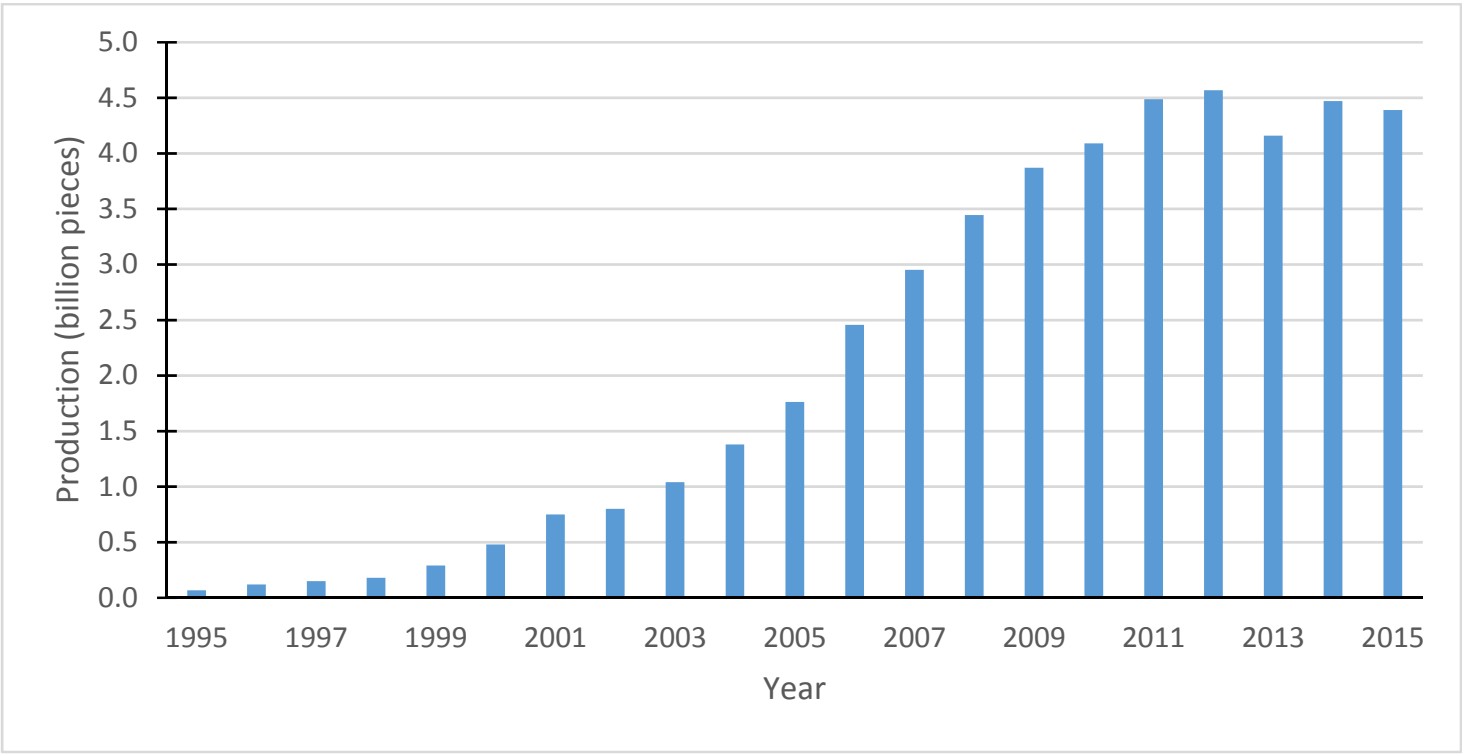

Figure 5: Production of CFLs in China (1995-2015)

(Sources: based on CIES, 2016; CIES, 2014; Lv \& Lv, 2012; Yu \& Zhou, 2001) 
The total CFL output was only about 66 million pieces in 1995, but it reached 4.57 billion in 2012. This growth represented an average annual growth rate of about $28.4 \%$ over this period. A large number of jobs were created, and a vast number of low-skilled laborers from rural China were trained to be skilled workers. At the end of 2015 , there were about 20,000 enterprises of various sizes in China's lighting industry, including manufacturers of both lighting bulbs and fixtures, which employed more than one million skilled workers (CIES, 2016). Most of these lighting enterprises are located in three regions of China - Yangtze River Delta, Fujian province and Guangdong province. These three lighting industrial clusters have formed their own full supply chain, which has helped the fast expansion of China's manufacturing capacity for efficient lighting products.

As a consequence of this program, many domestic incandescent lamp (IL) manufacturers have shifted to CFL production with technical and financial support from the central government. In 1995, the production of CFLs and ILs manufactured in China were 66 million and 2.9 billion pieces respectively, while production in 2014 grew to 4.47 billion pieces for CFLs and 3.29 billion pieces for ILs (Yu \& Zhou, 2001; CIES, 2016). The output ratio of the two types of bulbs (CFL/IL) produced in China increased dramatically from about 1:44 in 1995 to 1.36:1 in 2014.

\subsubsection{Global market player and export income}

China's lighting industry has been export-led. Being the biggest lighting products producer in the world, China accounts for about $80 \%$ of the global production of CFLs, and one-third of ILs (Xinhua News, 2014). A majority of the lamps manufactured in China are for export worldwide. The export ratio, namely export/total production in pieces, of CFLs and ILs has varied from about $60 \%$ to $80 \%$ over the past years (see Figure 6 ). 


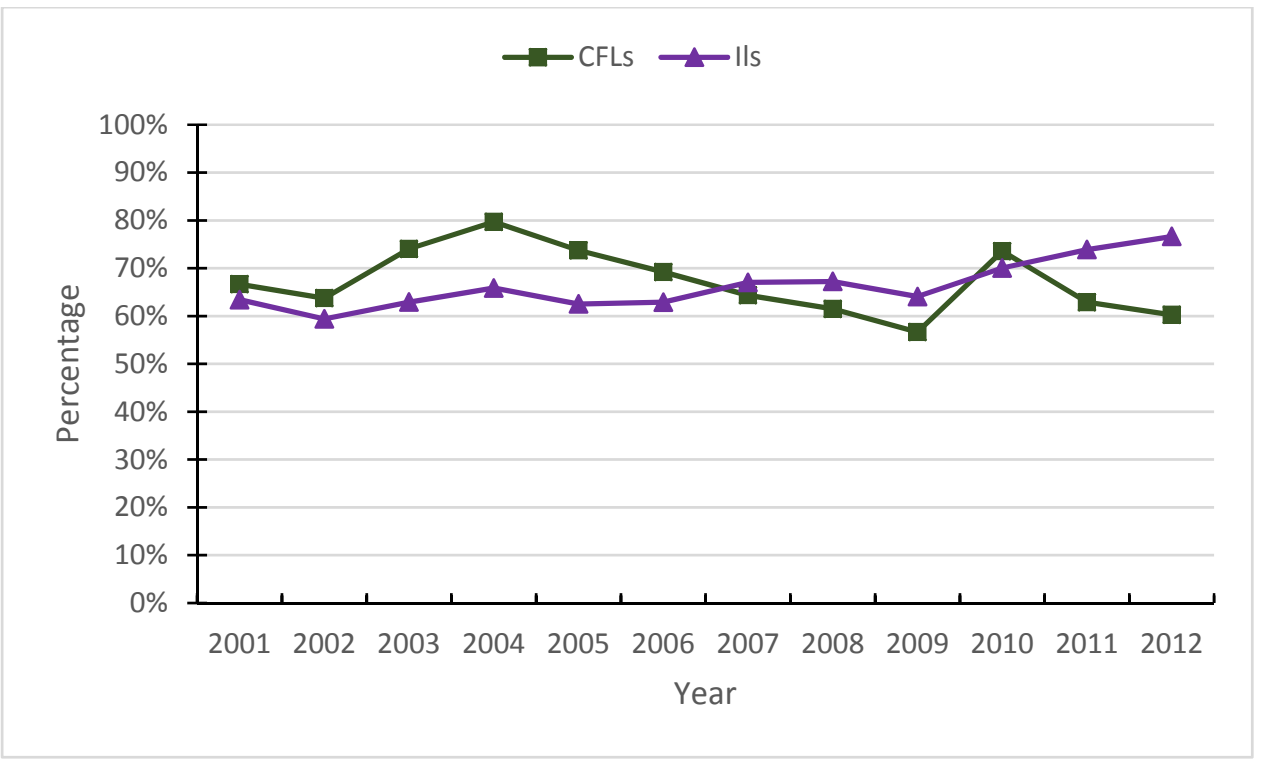

Figure 6: Export ratio of CFLs and ILs manufactured in China

(Sources: CIES, 2014; Lv \& Lv, 2012)

Based on the data from China's Illumination Engineering Society (CIES) (2016), the estimated total export of China's lighting products excluding lighting fixtures in 2015 was about 12.5 billion USD (see Table 8). Of this, CFLs and LED lamps accounted for about $20.7 \%$ and $53.1 \%$ respectively. However, as most of Chinese LED lighting producers are down-stream smallsized enterprises, and most of the required LED chips need to be imported, the LED lighting industry in China currently does not contribute to net exports. This may partly explain why LED lighting is currently more a focus of the Chinese government than CFLs.

Table 8: International trading of China's lighting industry products in 2015 (millions USD)

\begin{tabular}{|c|c|c|c|c|}
\hline \multicolumn{2}{|c|}{ Items } & Export & Import & Net export \\
\hline \multirow{3}{*}{ Lamps/bulbs } & CFLs & 2,583 & 7 & 2,576 \\
\cline { 2 - 5 } & ILs & 691 & 83 & 608 \\
\cline { 2 - 5 } & HIDs & 320 & 114 & 206 \\
\cline { 2 - 5 } & Other & 1,470 & 502 & 968 \\
\hline \multicolumn{2}{|c|}{ Ballast } & 773 & 48 & 725 \\
\hline \multicolumn{2}{|c|}{ LED products } & 6,618 & 7,402 & -784 \\
\hline \multicolumn{2}{|c|}{ Total } & 12,455 & 8,156 & 4,299 \\
\hline
\end{tabular}

(Source: authors' summary based on CIES, 2016) 


\subsection{Outstanding challenges for the next phase of the program}

Although the program had significant achievements over the past two decades, some challenges still remain. First, CFLs use is mostly concentrated in urban China, while the penetration in rural China is still very low. In 2010, the stock of China's incandescent bulbs used in households was about 1.28 billion pieces, with about $91.5 \%$ of these in use in rural villages (Lv \& Lv, 2012). As CFLs are several times the average price of ILs, they are, hence, still not affordable to many rural households. In addition, rural households are used to ILs, and mostly have low energy-saving awareness and concern. Promoting the wide application of CFLs in rural China remains a serious challenge for the Chinese government over the next phase of this program.

Second, most domestic lighting producers have focused only on lamp/bulb efficacy, but ignored the overall luminous efficacy of lighting fixtures, which has largely impeded the benefits of applying efficient lamps from being realized. A poor design of lighting fixtures often results in a luminous flux loss of more than $30 \%$. Therefore, setting standards for the overall performance of lighting fixtures is urgently needed in the country.

Finally, LED lamps are widely viewed as the strong market competitor for CFLs and other types of lamps in the foreseeable future. However, LED production is at a very initial stage in China now. The current issues in China's LED industry, such as insufficient LED lighting standards, poor interchangeability between different product brands, and poor product quality owing to low industry entering bar, deserve more government attention and need to be effectively addressed in the next phase of this program.

\section{Main lessons learnt from the Program}

Based on the above overview and assessment of China's Green Lights Program, several important lessons regarding the program and its implementation are uncovered, which can provide a useful guide for energy efficiency improvement activities in other developing countries that face similar challenges. 


\subsection{Strong and sustained government commitment}

Since its launch in 1996, China's Green Lights Program has been continuously highlighted by the central government and included in the nation's chief social and economic development plans, namely the 9th to 12th FYP. The program was always led by relatively powerful government agencies, first by the SETC from 1996 to 2003, and then by the NDRC after China's 2003 reform in government organization. In the Chinese government system, both of these two agencies are in a leading position to design wide-ranging national incentive policies, particularly with regard to combining energy efficiency policies with industrial development polices. Led by the SETC/NDRC, this program could be implemented on a stable and robust basis. This also crucially involved strong coordination of a number of central government agencies and managing the conflicting interest of different stakeholders. In short, strong and sustained commitment by powerful governmental agencies provided a concrete institutional basis for the program's success. Without this, it might have been difficult for this program to be continuously highlighted and included in the nation's FYPs.

\subsection{Prioritized focus by program stages}

A specific feature related to the implementation of China's Green Lights Program is that each FYP period had a prioritized policy focus. During the first stage (1996-1998), policy efforts were primarily focused on raising people's awareness of efficient lighting products. At the second stage (1999-2006), the program particularly emphasized enforcing domestic manufacturers to upgrade their product quality. At the end of this period, the Chinese public, particularly in urban areas, had already sufficient awareness about efficient lighting, and domestic manufacturers were able to deliver high quality products to the market. Accordingly, in the next period (2007-2010), the government at different levels implemented intensive subsidy programs to stimulate the demand and diffusion of efficient lighting products. In the latest 12th FYP period (2011-2015), the program started to focus more on emerging LED lighting products rather than CFLs. These are considered better both for improved lighting quality and people's eyesight, and for the environment as well since they eliminate mercury pollution. Prioritizing the policy focus by stages made the implementation of this program more practical, effective and efficient. 


\subsection{Extensive efforts on product quality control}

During its early stage, this program especially emphasized improving the product quality of domestic lighting manufacturers. To do so, a number of national standards of safety and performance for various lighting products were issued. A product 'energy conservation certification' and an energy efficiency labeling scheme were established to inform consumers about their purchase decisions. The technological conditions of different national lighting test centers (NLTC) were also raised to the same high standard in order to avoid misleading manufacturers and consumers by issuing different testing results for the same products. In addition, the central government conducted regular nationwide sample testing and inspection on lighting products' quality at both factories and in the marketplace. In comparison with imported efficient lighting bulbs, the domestic ones were much more affordable for Chinese consumers. The program's efforts on quality control significantly removed the previous cost barriers for high-quality efficient lighting products to Chinese consumers, and meanwhile largely reinforced the competitiveness of Chinese producers in the international market. The product quality control was a cornerstone of the success of this program.

\subsection{Successful combination of energy efficiency policies with industrial development policies}

Although not explicitly stated in its original objectives, China's Green Lights Program has inherently combined lighting energy efficiency policies with industrial development policies closely and consistently. This unique feature makes this program not only deliver significant environmental benefits such as electricity savings and lower pollutant emissions from power generation, but substantial economic benefits as well, including consumer savings, job creation, tax income and net exports. China's net export of lighting products of both lighting bulbs and fixtures in 2015 reached about 42 billion USD (CIES, 2016). The nation has become the largest global manufacturing center for lighting products, and about $60-80 \%$ of the annually produced lighting bulbs, namely ILs and CFLs, in China are exported (CIES, 2014).

\subsection{Combination of distinct and varying incentives}

This program adopted several types of incentive policies: mandatory, voluntary, informational and financial (see Figure 4). Many compulsory national standards of energy 
efficiency for various lighting products were issued. Inefficient products (i.e., ILs) were mandatorily required to be phased-out from the market by stages. Informational tools including a voluntary product certification scheme and a mandatory energy efficiency labelling scheme were established. A number of educational, training, demonstration, and awareness raising activities were conducted. Extensive large-scale subsidy programs were launched nationwide to facilitate the fast diffusion of efficient lighting products. In addition, several new market-based mechanisms were also adopted for expanding the demand for efficient products, through demand side management (DSM), energy performance contracts (EPC) by energy service companies (ESCOs), government procurement, and bulk purchase.

\section{Concluding remarks}

Triggered by the nationwide power shortage of the mid-1990s, the Chinese central government launched the Green Lights Program in 1996. Since then, this program has been continuously implemented in China for two decades.

The program primarily aimed to save electricity use, to slow down the investment needs for new power plants and reduce associated pollutant emissions, and to promote the quality of domestic efficient lighting products. With strong government commitment, extensive policy incentives were adopted by the program, particularly for disseminating information to the general public, establishing a high-level and uniform 'technological foundation' for the lighting industry and market, and facilitating the diffusion of efficient products on the demand side. A unique feature of this program lies in its successful combination of energy efficiency policies with industrial development policies.

With the implementation of this program over the past two decades, billions of efficient lighting products were disseminated in the country, which resulted in a significant amount of electricity saved and pollutant emissions reduced. At the same time, significant advancements in both the production capacity and technology level of domestic manufacturers of efficient lighting products occurred. The industry became able to provide high-quality efficient products to both Chinese and international markets at much more affordable prices than ever before. Lighting products manufacturing has become a rather prosperous industry in the country. China is currently the largest CFL producer in the world, 
accounting for $80 \%$ of total global CFL production. A majority of CFLs produced in the country, about $60-80 \%$, are for export worldwide, which brings back enormous export income every year.

In summary, the success of this programs can be attributed to several key factors: 1 ) strong and sustained government commitment; 2) prioritized policy focus by program stages; 3 ) extensive efforts on product quality control through mandatory national standards, product certification and energy efficiency labeling schemes, and the rigorous sampling test and inspection by the government; 4) a close symbiosis of energy efficiency policies with industrial development policies; and 5) the implementation of various incentive schemes. However, there are still a few outstanding challenges for the program to address in its next phase. These mainly include: 1) promoting the application of efficient lighting products in small towns and rural China with low household income; 2 ) emphasizing the overall luminous efficacy of lighting fixtures rather than focusing only on lamp/bulb efficacy, which could largely impede the benefits of applying efficient lamps from being realized; and 3) promoting the sustainable and healthy development of a LED lighting industry in China, which is just emerging in the country. 


\section{Acknowledgment}

The research leading to these results has been supported by the European Union's Horizon 2020 research and innovation programme under grant agreement No 642147 (CD-LINKS).

\section{Reference}

Aman M.M., Jasmon G.B., Mokhlis H., and Bakar A.H.A., 2013. Analysis of the performance of domestic lighting lamps. Energy Policy 52 (2013), pp. 482-500.

China Illuminating Engineering Society (CIES), 2014. China lighting market analysis (2009-2012). Available from: http://www.lightingchina.com/news/39083.html (accessed June 29, 2016).

CIES, 2016. Bulletin of Lighting Appliances 2016 (1).

China National Institute of Standardization (CNIS), 2011. White paper for the energy efficiency status of China energy-use products. China Zhijian Publishing House.

Collaborative Labeling and Appliance Standards Program (CLASP), 2011. Assessment of opportunities for global harmonization of minimum energy performance standards and test standards for lighting products. CLASP Report for the UNEP under the Contract No. UNEP SSFA/2011/GFL-5070-4EF1-27202302.

Guan F.M., Mills E., and Zhang Q., 1997. Energy efficient lighting in China: problems and prospects. Energy Policy 25 (1997) No.1, pp. 77-83.

Jiangmen City Government, 2013. Incentives for developing LED lighting industry in Jiangmen City (JM-2013-21). Available from: http://www.xhgcc.com/NewsView.asp?ID=1290\&SortlD=103 (accessed July 3, 2016).

Lighting Research Center at Rensselaer Polytechnic Institute (LRC-RPI), 2002. National Lighting Product Information Program (NLPIP): T5 Fluorescent Systems. Available from: http://www.Irc.rpi.edu/programs/nlpip/lightingAnswers/lat5/abstract.asp (accessed May 15, 2017).

Lin J., 1999. China Green Lights Program: a review and recommendations. LBNL Report 42183.

Liu H., 2012. China Green Lights Program in the past 20 years. Journal of China Illuminating Engineering, 2012 (S1), P12-17.

Liu et al., 2011. The implementation manual of China Green Lights. China Environmental Science Press, Beijing.

Liu H., 2009. The concept and practice of Green Lights. China Electric Power Press, Beijing.

Liu H, 2006. China's Green Lights Program: review of the past ten years and prospect. Energy of China, 2006(6), P17-22.

Lv F., and Lv W.B., 2012. The progress and prospect of green lights program in China. Journal of China Illuminating Engineering, 2012 (23), P1-6. 
Nadel S., Lin J., Yu C., Hinge, A., and Lv, W.B., 1999. The China Green Lights Program: a status report. ACEEE Report 1991.

National Development and Reform Commission of China (NDRC), 2005. China Green Lights Development Report (2004). China Electric Power Press, Beijing.

Pacific Northwest National Laboratory (PNNL), 2009. Performance of T12 and T8 Fluorescent Lamps and Troffers and LED Linear Replacement Lamps. CALiPER Benchmark Report (Prepared for the U.S. Department of Energy under Contract DE-AC05-76RL01830).

Pan D.M. et al., 2016. The development and data of China's semiconductor lighting industry 2015. China Solid State Lighting Alliance (CSA), Beijing.

Sina News, 2014. Subsidy program to energy-saving lamps ends this year. Available from: http://finance.sina.com.cn/roll/20140607/025719341515.shtml (accessed July 3, 2016).

State Council Information Office of China (SCIO), 2006. NDRC press conference on Green Lights Program. Available from:

http://www.scio.gov.cn/xwfbh/gbwxwfbh/xwfbh/fzggw/document/313370/313370.htm (accessed June 27, 2016).

State Economic and Trade Commission of China (SETC), 1996. Implementation scheme of China's Green Lights Program.

Suning, 2017. Price of lighting products. Available from: https://www.suning.com/ (accessed May 12, 2017).

United Nations Development Programme (UNDP), 2009. Phasing-out of incandescent lamps \& energy saving lamps promotion (PILESLAMP) project (PIMS\# 4166). UNDP Project Document.

U.S. Agency for International Development (USAID), 2010. Quality control and market supervision of compact fluorescent lamps in China.

U.S. Department of Energy (U.S. DOE), 2017. CALiPER Snapshot Industrial Luminaires. Available from: http://www.lightingfacts.com/Downloads/LightingFactsSnapshot-Industrial.pdf (accessed May 14, 2017).

U.S. DOE, 2013. Lighting Basics. Available from:

https://energy.gov/eere/energybasics/articles/lighting-basics (accessed May 14, 2017).

World Bank, 2017. Online Data: GDP deflator of China. Available from:

http://data.worldbank.org/indicator/NY.GDP.DEFL.ZS?locations=CN (accessed July 9, 2017).

Xinhua News, 2014. Twenty-one cities in Hubei province commitment to phase-out incandescent bulbs before 2017. Available from: http://news.xinhuanet.com/politics/2014-

10/14/c 1112823974.htm (accessed July 3, 2016).

Yu C., and Zhou D.D., 2001. Evaluation of the implementation of China's green lights program. Energy of China, 2001(2), P8-11.

Zhang S., and Qin X., 2015. Lessons learned from china's residential tiered electricity pricing reform. Reports of International Institute for Sustainable Development (IISD). 
Zheng et al., 2016. Chinese household energy consumption report 2015. Science Press Ltd., Beijing. 